\title{
To study the antidandruff activity of rosemary oil, basil oil, coleus oil over selenium sulfide
}

\author{
Patil Trupti K ${ }^{1}$, S. S Gadekar ${ }^{2}$ \\ ${ }^{1}$ Department of Cosmetics, R.C. Patel Institute of Pharmaceutical Education \& Research, Shirpur - 425 405, Maharashtra, India, ${ }^{2}$ Department of Pharmacognosy, R.C. Patel \\ Institute of Pharmaceutical Education \& Research, Shirpur - 425 405, Maharashtra, India
}

\begin{abstract}
Dandruff is caused by Malassezia (Pityrosporum) species. Dandruff is controlled by fungistatic ingredients in Antidandruff shampoos. Comparative study on the effectiveness of chemical and herbal antidandruff ingredients and their performance in shampoos was done in vitro against Malassezia furfur. Selenium Sulfide has a good antidandruff activity along with the chemical ingredients. Herbal ingredients such as rosemary oil, basil oil, and coleus oil also have an antidandruff activity, but their minimum inhibitory concentration (MIC) values are much more than the synthetic ingredients. Essential oils can be great allies in the fight against fungi/dandruff. Most of the essential oils are excellent antibacterial and antifungal treatment making an excellent fighter against dandruff. The antifungal activities of essential oils and synthetic chemical, i.e., selenium sulfide were analyzed towards $M$. furfur. The data obtained indicated that rosemary essential oil exhibited the strongest inhibitory activities. MIC of rosemary oil against $M$. furfur was at $0.5 \%$. Basil oil is also possessed considerable antifungal activity, and MIC of Basil oil against $M$. furfur was at $0.7 \%$. Coleus essential oil exhibited the minimum inhibitory activity at $0.9 \%$ while that of selenium sulfide possessed considerably lower antifungal activity than these essential oils and was measured at $2.5 \%$. The results of MICs revealed that the rosemary, basil, and coleus essential oils exhibited the best antifungal activities toward $M$. furfur than that of selenium sulfide.
\end{abstract}

Correspondence:
Patil Trupti K. Department of B. Tech (Cosmetics), R.C. Patel Institute of Pharmaceutical Education \& Research, Near Karwand Naka, Shirpur - 425 405, Dhule, Maharashtra, India. Phone: +91-9665442471. E-mail: ptrupti081@gmail.com
Keywords: Antidandruff activity, dandruff, Malassezia, pityrosporum, shampoos

\section{INTRODUCTION}

Dandruff is a common scalp disorder which affects almost half of the young population of both genders. The pathogenesis involves hyperproliferation of dandruff which is resulting in deregulation of keratinization. The causative agents of dandruff are group of scalp commensal lipophilic yeasts of the genus, Malassezia. ${ }^{[1]}$ Exterminate or controlling the scarcity of yeasts appears to be the cleverest approach for treating dandruff. Using different methods, clinical as well as experimental protocols and distinct active ingredients, all signify that applying antifungal based antidandruff (AD) shampoos lead to a stereotyped progression of events. Several fungistatic compounds improve dandruff condition. The main active ingredients include

\section{Access this article online}

Website: http://www.jpbs-online.com

E-ISSN: $2321-0125$

DOI: $10.31555 / j p b s / 2018 / 6 / 2 / 36-39$

How to cite this article: Trupti PK, Gadekar SS. To study the antidandruff activity of rosemary oil, basil oil, coleus oil over selenium sulfide. J Pharm BioSci 2018;6(2):36-39.

Source of Support: Nil, Conflict of Interest: None declared. imidazole derivatives such as ketoconazole and other compounds such as selenium sulfide also the AD products are to remove scales, reduce Malassezia (Pityrosporum) observance of corneocytes and suppress the yeast growth. In addition to that, there is a wide range of herbal ingredients such as rosemary oil, basil oil, and coleus oil which have been known to have good antipityrosporum or AD activity. ${ }^{[2,3]}$

There are numerous independent studies on these chemical or herbal actives and their effectiveness in AD shampoos. Still, there is no comprehensive comparative in vitro study on the AD efficacy of the chemical and herbal actives formulation (AD shampoo).

Hence, the present study was undertaken. The microbial strains, which were used in this experiment are Malassezia furfur.

\section{MATERIALS AND METHODS}

All natural and synthetic ingredients such as rosemary oil and coleus oil were procured from Kingvish Kompany, Basil oil were procured from katyani exports, and Selenium sulfide were procured from Croda Chemicals Pvt Ltd. M. furfur were procured from Rajiv Gandhi Institute of Biotechnology, Rashtrasant Tukdoji Maharaj University. 


\section{Extraction of essential oils}

Essential oils are generally extracted by distillation. Other processes include expression or solvent extraction. Essential oils are produced from a different type of flowers, leaves, and herbs by steam distillation or by solvent extraction process using organic solvents, such as ethyl alcohol or hexane. Distillation temperature varied for a different variety of herbs. Condensation of distillate is depend on cooling temperature. Condensation of essential oil vapor is controlled by cooling coil or jacketed on the steam reactor vessel. The steam reactor vessel is made by mild steel or by stainless steel. Heat sources used as steam and sometimes solvent used hexane or alcohol for the extraction of essential oil from leaves, flowers, or herbs. Extracted oil is separated by low-temperature vaccum distillation process. ${ }^{[4]}$ Each essential oils consist of several, sometimes hundreds of distinct natural chemicals. Many of these have antimicrobial and antifungal activity and show synergistic effects. Essential oils can be great allies in the fight against fungi/ dandruff. The various natural essential oils are used in the treatment for dandruff of their antifungal property. Most of the essential oils are excellent antifungal properties. ${ }^{[5]}$ The natural essential oils like rosemary oil, coleus oil, and basil oil are used to prevent dandruff. Thus by proper type and the amount of essential oil in the product can give most effective treatment against dandruff without causing any side effect than synthetic chemicals. ${ }^{[6]}$

\section{Details of actives (Table 1): ${ }^{[6-9]}$}

\section{Formulation and development of shampoo}

For the incorporation of the active ingredients in the formulation, and for a proper release of the active from the formulation to get desired therapeutic activity, base plays an important role.

Therefore, the base should possess the following properties.

- A base must have aesthetical appeal.

- It should not counteract to the properties of active.

- Being a vehicle for active ingredient base must be able to.

- Dissolve it or at least finely dispersed it well.

The raw material in the base should be compatible with each other, well as with active ingredient. ${ }^{[10,11]}$

\section{Preparation of shampoo base (Table 2)}

\section{Procedure}

1. Phase A and B were melt up to $75^{\circ} \mathrm{C}$.

2. Continuous and slowly stirring was applied for both phases to avoid foaming during heating.

3. Phase $\mathrm{A}$ was mixed in phase $\mathrm{B}$ with constant and vigorous stirring.

4. At $45^{\circ} \mathrm{C}$, phase $\mathrm{C}$ was added and mixed well.

Table 1: Details of actives

\begin{tabular}{|c|c|c|c|}
\hline Rosemary oil & Basil oil & Coleus oil & Selenium sulfide \\
\hline $\begin{array}{l}\text { Synonym: } \\
\text { Flowering rosemary, prostratus } \\
\text { rosemary, romeo rosemary }\end{array}$ & $\begin{array}{l}\text { Synonym: } \\
\text { Sacred basil, Holy basil, Sweet basil, Thai } \\
\text { basil }\end{array}$ & $\begin{array}{l}\text { Synonym: } \\
\text { Coleus Barbatus, Coleus Grandis, } \\
\text { Coleus Penzigii, Coleus Vestitus, Wild } \\
\text { Oregano, Makandi }\end{array}$ & $\begin{array}{l}\text { Empirical formula: } \\
\mathrm{SeS}_{2} \\
\text { Molecular weight: - } 143.09 \mathrm{~g} / \mathrm{mol}\end{array}$ \\
\hline $\begin{array}{l}\text { Biological source: } \\
\text { It is the volatile oil obtained from fresh } \\
\text { flowering tops of the plant Rosmarinus } \\
\text { officinalis Linn, belonging to the family } \\
\text { Labiatae } \\
\text { Chemical constituents: } \\
\text { The flower contains volatile oil, resin, } \\
\text { ursolic acid and bitter principle while } \\
\text { leaves, in addition to oil also contain } \\
\text { borneol, bornyl acetate, camphor } \\
\text { eucalyptol, pinene, d-camphene, } \\
\text { cineole and terpenes. The oil } \\
\text { contain terponeol, trans-carveol, } \\
\text { caryophyllene, caryophyllene dioxide, } \\
\text { santalol etc. }\end{array}$ & $\begin{array}{l}\text { Biological source: } \\
\text { Basil essential oil is extracted by steam } \\
\text { distillation from the leaves and flowering } \\
\text { tops of Ocimum basillicum to the family } \\
\text { Labiatae } \\
\text { Chemical constituents: } \\
\text { It has various chemical compounds } \\
\text { that include a-pinene, camphene, } \\
\text { b-pinene, myrcene, limonene, camphor, } \\
\text { linalool, citronellol, geraniol, methyl } \\
\text { cinnamate, and eugeneol. The oil contain } \\
\text { cineol, d-linalool (about } 40 \% \text { ) methyl } \\
\text { chavicol (about } 25 \% \text { ), p-cymene, } \\
\text { a-terpinol and some sesquterpenes } \\
\text { hydrocarbons }\end{array}$ & $\begin{array}{l}\text { Biological source } \\
\text { It is a diterpene isolated from roots of } \\
\text { Coleus forskohlii, belonging to the family } \\
\text { Labiatae } \\
\text { Chemical constituents: } \\
\text { It contains forskolin (coleonol), } \\
\text { thymol, terpene, eugenol, trans } \\
\text { caryophyllene oxide and alpha - cadinol. } \\
\text { The leaves contain methylenequinone, } \\
\text { barbatusin and roots contain } \\
\text { coleonol B, deoxycoleonol. The oil } \\
\text { contain 1, 3-hexadiene, hexanol, } \\
\text { myrcene, p-cymene linalool, } \\
\text { terpine-4-ol and carvacrol }\end{array}$ & $\begin{array}{l}\text { Physical properties: } \\
\text { Selenium Sulfide is an inorganic salt } \\
\text { including of selenium and sulfur. } \\
\text { Naturally occurring Selenium is } \\
\text { mineral element which is found in } \\
\text { rocks and soil. In nature, Selenium } \\
\text { is usually combined with sulfide. } \\
\text { Selenium is an essential trace mineral } \\
\text { found in the active center of certain } \\
\text { enzymes }\end{array}$ \\
\hline $\begin{array}{l}\text { Cosmetic uses: } \\
\text { It has antifungal, antibacterial } \\
\text { properties to kill bacteria and fungi. } \\
\text { The rosemary is beneficial to skin } \\
\text { the same way it helps with dandruff, } \\
\text { by relieving dryness and providing } \\
\text { nourishment. } \\
\text { It helps to treat dandruff because it has } \\
\text { antifungal properties. } \\
\text { It is used as a fragrant component in } \\
\text { a creams, lotion, shampoo, soaps and } \\
\text { perfumes }\end{array}$ & $\begin{array}{l}\text { Cosmetic uses: } \\
\text { It helps to minimize dandruff and hair } \\
\text { loss by stimulating hair follicles. It also } \\
\text { helps in relieving itching and flaking scalp } \\
\text { and dandruff. It encourages hair growth } \\
\text { through stimulating blood circulation and } \\
\text { adds luster to dull looking hair. It is used } \\
\text { in various cosmetics such as lotions, soaps, } \\
\text { shampoo and perfumes. }{ }^{[6,7]}\end{array}$ & $\begin{array}{l}\text { Cosmetic uses: } \\
\text { It has good antipityrosporum or } \\
\text { antidandruff, antibacterial and } \\
\text { anti-inflammatory properties. It can be } \\
\text { used as a flavouring agent. It is used in } \\
\text { various cosmetics such as lotions, soaps, } \\
\text { shampoo and perfumes. It helps to treat } \\
\text { dandruff and micro-organism associated } \\
\text { with acne and other skin infections. }{ }^{[7]}\end{array}$ & $\begin{array}{l}\text { Cosmetic uses: } \\
\text { Selenium Sulfide may increase } \\
\text { the appearance and feel of hair, } \\
\text { by growing hair body, agility } \\
\text { or sheen, or by improving the } \\
\text { texture of hair that has been } \\
\text { damaged physically or by chemical } \\
\text { treatment. Selenium Sulfide } \\
\text { also helps to manage dandruff, } \\
\text { seborrhea dermatitis and psoriasis. } \\
\text { It controls dandruff via its anti } \\
\text { Malassezia effect rather than by its } \\
\text { antiproliferative effect }\end{array}$ \\
\hline
\end{tabular}




\section{Evaluation of anti-microbial and antifungal activity}

a) Minimum inhibitory concentration (MIC)

The MIC or MIC test determines antifungal activity of a material against specific fungi. Agar diffusion method is employed for the MIC or MIC.

The MIC or MIC is the smallest concentration of an antibacterial and antifungal agent that inhibits the growth of bacteria or fungi.

\section{Principle}

The agar well diffusion method has been used for evaluating antibacterial and antifungal activities of a variety of compounds. The activity of compounds is indicated by a clear zone around the "well," a hole cut in the agar and filled with the test sample. The inhibition zone around the compounds denotes resistance to microbial growth.

\section{Procedure}

\section{Preparation of media M. furfur}

The culture of $M$. furfur was cultivated and maintained on a growth medium described below. The incubation was done at room temperature for 7 days.

\section{Potato dextrose agar (PDA)}

$39 \mathrm{~g}$ of PDA and $5 \mathrm{~g}$ agar-agar were weighed and transferred to $1000 \mathrm{ml}$ borosil beaker to this $1000 \mathrm{ml}$ of distilled water was added and was stirred on water bath for $20 \mathrm{~min}$ until frothing appears during heating. Then sterilization was done in an autoclave at $121^{\circ} \mathrm{C}$ and $1.05 \mathrm{~kg} \mathrm{f} / \mathrm{cm}^{2}$ pressure for $20 \mathrm{~min}$. After sterilization it was kept in refrigerator. ${ }^{[12]}$

b) MIC of selected active against $M$. furfur

MIC of selected active against $M$. furfur was estimated by Agar well diffusion method.

\section{Procedure}

1. All the apparatus and media were sterilized in an autoclave at $121^{\circ} \mathrm{C}$ and $1.05 \mathrm{~kg} / \mathrm{cm}^{2}$ pressure for $20 \mathrm{~min}$.

2. The sterile and melted media were cooled at $45^{\circ} \mathrm{C}$, then poured in labeled Petri plates and allowed to solidify.

3. After solidification of media, the pure culture of M. furfur was spread on the solidified media for respective species.

4. The wells were made in each Petri plates with the help of sterile cork borer.

5. Now with the help of sterilized pipette different concentration such as $0.1 \mathrm{ml}, 0.2 \mathrm{ml}, 0.3 \mathrm{ml} \ldots$ of rosemary oil, basil oil and coleus oil and $2 \mathrm{ml}, 2.1 \mathrm{ml}, 2.2 \mathrm{ml} \ldots$ of selenium sulfide were poured in the well.

6. Then all plates were incubated at $37^{\circ} \mathrm{C}$ for $48 \mathrm{~h}$.

7. The activity of actives is indicated by a clear zone of inhibition around the discs. These zones were measured and recorded.

Antifungal activity of rosemary oil, basil oil, coleus oil and selenium sulfide (Tables 3 and 4). ${ }^{[5,13]}$
Table 2: Formulation of shampoo base

\begin{tabular}{llccc} 
S. No. & Ingredients & \multicolumn{3}{c}{ Quantity in \% (w/w) } \\
\cline { 3 - 5 } & & Trial 1 & Trial 2 & Trial 3 \\
Phase A & & & \\
1 & Sodium lauryl ether sulfate & 33.5 & 35 & 35 \\
2 & Coco amido propyl betain & 2.5 & 3 & 3 \\
3 & Coco diethanol amide & 2.5 & 2.5 & 2.5 \\
4 & Ethylene glycol monostearate & 2.2 & 2.5 & 2.7 \\
Phase B & & & & \\
1 & Coco monoethanol amide & 2.5 & 2.5 & 2.5 \\
2 & Propylene glycol & 4.5 & 5 & 5 \\
3 & Distilled water & 55.3 & 50.2 & 47.8 \\
4 & Methyl paraben & 0.4 & 0.4 & 0.4 \\
Phase C & & & & \\
1 & Sodium chloride & 0.5 & 0.8 & 1 \\
2 & Ethylene diaminetetraacetic acid & 0.1 & 0.1 & 0.1 \\
\hline
\end{tabular}

Table 3: MIC and ZOI of synthetic and herbal ingredients

\begin{tabular}{llcc} 
S. No. & Sample & MIC $(\mathbf{m l})$ & ZOI $(\mathbf{m m})$ \\
Synthetic ingredient & & & \\
1 & Selenium sulfide & 2.5 & 7 \\
Herbal ingredient & & & \\
1 & Rosemary oil & 0.5 & 7 \\
2 & Basil oil & 0.7 & 7 \\
3 & Coleus oil & 0.9 & 7 \\
\hline
\end{tabular}

\section{Stability study for finished product}

All the samples prepared were subjected to accelerated test conditions and were kept at room temp in oven at $45 \pm 2{ }^{\circ} \mathrm{C}$ and in refrigerator at $4 \pm 2{ }^{\circ} \mathrm{C}$.

Stability studies were carried out by accelerated stability test for 60 days.

\section{RESULT AND DISCUSSION}

The essential oils, i.e., rosemary oil, basil oil, coleus oil possess antifungal properties. An attempt was made to compare this natural essential oil against synthetic chemical, i.e., selenium sulfide as an AD agent.

The antifungal activities of essential oils and synthetic chemical, i.e., selenium sulfide were analyzed towards $M$. furfur.

The data obtained indicated that rosemary essential oil exhibited the strongest inhibitory activities. MIC of rosemary oil against $M$. furfur was at $0.5 \%$.

Basil oil is also possessed considerable antifungal activity, and MIC of basil oil against $M$. furfur was at $0.7 \%$. 
Table 4: Antidandruff activity of Shampoos with synthetic and herbal active ingredients

\begin{tabular}{lccc}
$\begin{array}{l}\text { Antidandruff shampoo with } \\
\mathbf{0 . 5 \%} \text { rosemary oil }(\mathbf{m m})\end{array}$ & $\begin{array}{c}\text { Antidandruff shampoo with } \\
\mathbf{0 . 7 \%} \text { basil oil }(\mathbf{m m})\end{array}$ & $\begin{array}{c}\text { Antidandruff shampoo with } \\
\mathbf{0 . 9 \%} \text { coleus oil (mm) }\end{array}$ & $\begin{array}{c}\text { Antidandruff shampoo with } \\
\mathbf{2 . 5 \%} \text { selenium sulfide (mm) }\end{array}$ \\
\hline 7 & 5 & 7 & 5 \\
\hline
\end{tabular}

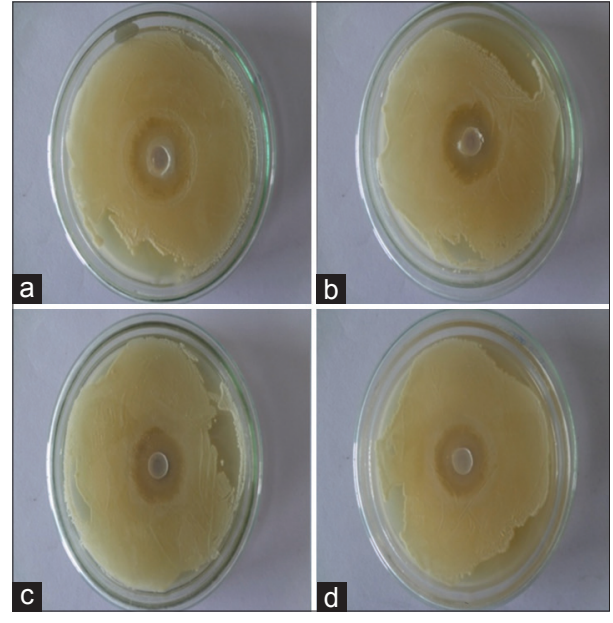

Figure 1: (a) Formulation with $0.5 \%$ rosemary oil, (b) formulation with $0.7 \%$ basil oil, (c) formulation with $0.9 \%$ coleus oil, (d) formulation with $2.5 \%$ selenium sulfide

Coleus essential oil exhibited the minimum inhibitory activity at $0.9 \%$ while that of selenium sulfide possessed considerably lower antifungal activity than these essential oils and was measured at $2.5 \%$.

The results of MICs revealed that the rosemary, basil, and coleus essential oils exhibited the best antifungal activities towards $M$. furfur than that of selenium sulfide.

\section{CONCLUSION}

Dandruff is a condition of the scalp characterized by the massive desquamation of small flakes of stratum corneum. The scales may be or trapped in film of sebum. It is caused by the fungus $M$. furfur that occurs when the dead skin is dead, producing irritating white flakes and itchy scalp.

Selenium sulfide is widely used nowadays because its popularity has increased in recent years with the emergence of antibiotic-resistant strains of $M$. furfur.

As this is a synthetic chemical and using it may show various side effect. Thus, after studying the antifungal properties natural essential oil which shows comparable response with selenium sulfide for acting against $M$. furfur. Hence, it is consider to be a good option than synthetic chemical.

The essential oils were added in simple shampoo base which prevents the dandruff from the hair. Thus after testing, they show better result than selenium sulfide.

This result revealed that essential oils act comparable against dandruff than selenium sulfide.

\section{REFERENCES}

1. Tortora GJ, Derrickson BH. Principles of Anatomy and Physiology. $12^{\text {th }}$ ed., Vol. 1. Hoboken, NJ: Universal Publishing Corporation; 2009. p. 157.

2. Thomas D. Malassezia species and the cause of dandruff: Cosmetic and Toiletories; 2002. Vol-II. p. 44.

3. Woods GL, Gutierrez Y. Diagnostic Pathology of Infectious Diseases. $1^{\text {st }}$ ed. New Delhi: Oxford University Press; 1993. p. 418.

4. NIIR Board. Essential oils. Modern Technology of Perfumes, Flavor and Essential Oil. $2^{\text {nd }}$ ed. New Delhi: NIIR Board of Technology. p. 37, 38.

5. Kalemba D, Kunicka A. Antibacterial and antifungal properties of essential oil. Curr Med Chem 2003;10:813-29.

6. Skidmore-Roth L. Handbook of Herb and Natural Supplement. $2^{\text {nd }}$ ed. St. Louis: Mosbey; 2010. p. 42.

7. Kokate CK, Gokhale SB. Pharmacognosy. $34^{\text {th }}$ ed. Pune: Nirali Prakashan; 2006. p. 56, 348, 355, 387.

8. Saleem AM, Dhasan PB, Rafiullah MR. Simple and rapid method for the isolation of forskolin from Coleus forskohlii by charcoal column chromatography. J Chromatogr A 2006; 1101:313-4.

9. Lawrence B.M. The journal of oil research. The antimicrobial and biological activity of essential oil; Published by Allured global information leader; P.213, $214,215$.

10. Wilkinson JB, Moore RJ. Harry's Cosmeticology. $7^{\text {th }}$ ed. New York: Chemical Publishing Company Inc.; 1990. p. 19, 418, 419.

11. Marvin BS, Edward S. Cosmetic Science \& Technology. $2^{\text {nd }}$ ed. Vol-II. New York: Interscience Publishers, Inc.; 1957. p. 183.

12. Ananthanarayan R, Paniker JC. Textbook of Microbiology. New Delhi: Orient Longman Ltd.; 1996. p. 566, 567.

13. Chhavi S, Sushma D, Ravinder V, Anju D, Asha S. Int Res J Pharm IRJP 2011;2. 